\title{
Sınıf Öğretmenlerinin Görüşlerine Göre İlkokulda Uygulanan Oyun ve Fiziki Etkinlikler Dersinin Değerlendirilmesi
}

\section{Evaluation of Play and Physical Activities Course Taught in Elementary Schools on the basis of Classroom Teachers' Opinions}

\author{
Süleyman $\mathrm{CAN}^{1}$, Gözde ÇAVA ${ }^{2}$
}

\begin{abstract}
Öz: Araştırmanın amacı, ilkokulda çalışan sınıf öğretmenlerinin programda yer alan oyun ve fiziki etkinlikler dersi hakkındaki görüşleri ortaya koymaktır. Araştırma nitel araştırma yöntemlerinden durum çalıșması kullanılarak desenlenmiştir. Araştırmanın çalışma grubunu 2014-2015 eğitim öğretim yılında Muğla ili Menteşe ilçesinde çalışan ve gönüllü olarak katılan 20 sinıf öğretmeni oluşturmaktadır. Araştırmada veriler amaca uygun olarak hazırlanan açık uçlu sorular ile toplanmış, analizinde betimsel analiz kullanılmıştır. Araştırma sonucuna göre öğretmenler; oyun ve fiziki etkinlikler dersinin kazanım, ders kitabı ve etkinlikler açısından sorunlar taşıdığını; oyun ve fiziki etkinlikler dersinde kullanılabilecek araç-gereçlerin temin edilemediğini ortaya koymuşlardır.
\end{abstract}

Anahtar sözcükler: Oyun ve fiziki etkinlikler dersi, oyun, ilkokul ögrencisi, sinıf ögretmeni

\begin{abstract}
The purpose of the current study is to elicit the opinions of the classroom teachers working in elementary schools about the course of play and physical activities in the elementary school curriculum. The current study was designed by using the case study, one of the qualitative research methods. The study group of the current research is comprised of 20 classroom teachers working in the Menteşe province of the city of Muğla in 2014-2015 school year, participating on a voluntary basis. The data of the study were collected through open-ended questions developed for the purpose of the study and in their analysis, descriptive analysis was used. The results of the study revealed that the teachers are of the opinion that the course of play and physical activities has some problems in terms of expected outcomes, textbook and activities and tools-equipments that can be used in the course of play and physical activities are not supplied.
\end{abstract}

Keywords: Play and physical activities course, play, elementary school student, elementary school teacher

${ }^{1}$ Doç. Dr., Muğla Sitkı Koçman Üniversitesi, e-posta: scan@mu.edu.tr

2 Ünvan 2, Üniversite adı 2, e-posta: 


\section{GIRİŞ}

Çağımız eğitim anlayışında ezberin yerine bilginin uygulamalarda kullanılması kabul edilmiştir. Eğitim çocukların problem çözmelerini, güven duymalarını, çok boyutlu düşünebilmelerini ve buluş yapmalarına olanak sağlayan, yaratıcılığını ve güçlüklerle başa çıkabilme becerilerini geliştiren birey olmayı hedeflemektedir. Öğrenciler eğitim yolu ile aktif, düzenli ve sağlıklı yaşam becerilerini, temel hareketleri, kavramları ve stratejileri kazanarak bir sonraki eğitim seviyesine hazırlanmaları istenilmektedir (MEB, 2012a). Bu nedenle 2012-2013 eğitim öğretim yılında başlamak üzere ilkokul ders programlarına dahil edilen oyun ve fiziki etkinlikler dersi önem taşımaktadır.

Oyunun geçmişi eski zamanları kapsadığından oyunla ilgili çeşitli ve çok yönlü tanımlar yapılmıştır. Oyun, günlük aktivitelerin dışında bir amaç doğrultusunda fiziksel ve zihinsel becerilerle yapılan, belirli yer-zaman ve kuralları bulunan, gönüllülüğe dayalı olarak sosyal ve duygusal olgunluğu geliştiren, beceri, zeka, dikkate dayanan, katılanları ve izleyicileri etkisinde bırakan, maddi bir çıkarın olmadığı, gerilim duygusunun olduğu zevk veren bir etkinliktir (Özdenk, 2007). Oyun geniş bir çerçeveden bakıldığında çocuğun kişilik oluşumunu tamamen etkileyen bir faaliyettir (Uluğ, 1999). Çeşitli tanımlar yapılsa da genel anlamıyla oyun çocuğun hoşlanarak ve isteyerek yaptığı, fiziksel, bilişsel, dil, duygusal ve sosyal gelişimini sağlayan, gerçek hayattan örneklerin bulunduğu ve çocuğa yaparak öğrenme ortamı sağlayan, çocuğun çevreyle etkileşim halinde olduğu bir etkinliktir.

Oyunun yapısal temelleri (Can, 2015; MEB, 2012b):

1) Kavramsallık: Oyuna katılan bireylerin kabiliyet ve becerilerine yöneliktir. Oyundaki farklı karakterdeki rolleri oyuncunun üstlenmesi, oyuna ilişkin taktik yaratması ya da geleneksel oyunu kullanıp kullanmamasıdır.

2) İsteklilik: Oyun oynamaya karşı isteklilik ve arzudur.

3) Keyiflilik: Oyuncunun farklı duygu ve hareketler içerisinde yer alarak oyundan zevk almasidir.

4) Motivasyon: Hedef dayalı davranışları başlatan ve devam ettiren süreçtir.

5) Fiziksellik: Bireyin oyundaki psikomotor hareketlerini ve koordinasyon içerir.

6) Sosyallik: Bireyin, oyun sırasında paylaşma, yardımlaşma yapma durumu ile oyunun sürükleyiciliği, diğer insanlara gösterdiği yakınlık gibi oyun arkadaşlarıyla kurduğu ilişkileri kapsar.

İlkokul çocuğunun duyuşsal, bilişsel, fiziksel, ve sosyal yönden gelişimini katkı sağlayan önemli unsurlardan birisi de oyundur. Çocuğun sağlıklı bir şekilde büyümesinde etken olan beslenme ve sevgi kadar oyun da önem taşımaktadır. Çocukluk döneminde temel amaçlardan olan öğrenme, tecrübe kazanma, yaratma, iletişim kurma ve yetişkinliğe hazırlanma süreçlerince oyun bir araç olarak kullanılmaktadır. Oyun bir araç olarak duyguları ifade etmeyi sağlayan, sıkıntılardan kurtulmaya olanak yaratan, serbestlik sağlayan, haz ve mutluluk veren, çocuğu eğlendiren ve geliştiren, tüm gelişim alanlarını destekleyen etkinliklerin tümüdür (Poyraz, 1999).

Oyun tüm gelişim alanlarını doğrudan doğruya etkileyen bir etkinliktir. $\mathrm{Bu}$ etkiler her oyunun özelliklerine göre farklılık göstermekle birlikte bireyin gelişimini 
bir bütün olarak etkilediği bir gerçektir. Oyunun faydalarını şöyle özetleyebiliriz (Cihangiroğlu, 1994; Erdem, 2003).

1) Öğrencilerinin bedenini tanımasını sağlar.

2) Oyun öğrencilerin duygusal ve sosyal gelişimini sağlar.

3) Öğrencilerin kendini tanımasını sağlamaktadır.

4) Oyun öğrencileri hayata hazırlar.

5) Öğrenci oyun oynarken, bencillikten uzaklaşan, saygı duyan, kendi hak ve özgürlüklerini koruyan, rekabet, liderlik, birlikte çalışma, yenme yenilme, yardımlaşma dayanışma, kendi ile barışık olma ve kendine güven duymayı öğrenir.

6) Öğrenci oyunla, öğrendiği bilgileri uygulama ve geliştirme olanağı bulur.

7) Düşünmeyi sağlayarak fikir üretme alışkanlığı kazanmayı ve bunları uygulamada görme firsatını sunar.

8) Öğrencinin iletişim becerisini geliştirir.

Oyun ve fiziki etkinlikler dersi ilkokulda öğrencilerin oyun oynama, fiziksel etkinliklere katılma sürecinde kişisel, zihinsel, bedensel, sosyal ve duygusal becerilerini geliştirmeye katkı sağlayan eğitim sürecini barındırır. Oyun ve fiziki etkinliklerin eğitim sürecinde öğrencinin hazırbulunuşluk, yaş, ilgi, beklenti ve yöresel özellikler gibi etkenler dikkate alınır. Bu sebeplerden dolayı araştırmacıların ilgisini çekmiştir. Buradan hareketle ilkokulda dersin işlenişinin nasıl yapıldığ 1 , derse ilişkin yaşanan sorunların olup olmadığına ilişkin öğretmenlerin görüşlerinin belirlenmesine gerek duyulmuştur.

\subsection{Araştırmanın Amacı}

Araştırma kapsamında, oyun ve fiziki etkinlikler dersinin ilkokullarda görev yapan sınıf öğretmenlerinin görüşleri doğrultusunda değerlendirilmesi amaçlanmıştır. $\mathrm{Bu}$ ana amaçtan hareketle araştırma kapsamında aşağıdaki sorulara cevap aranmıştır:

1) Sınıf Öğretmenlerinin oyun ve fiziki etkinlikler dersinin kazanımlarına ilişkin görüşleri nasıldır?

2) Sınıf Öğretmenlerinin oyun ve fiziki etkinlikler dersine ilişkin hazırlanan ders kitapları hakkındaki görüşleri nelerdir?

3) Sınıf Öğretmenlerinin oyun ve fiziki etkinlikler dersinde daha çok öncelik verdikleri etkinlikler hangileridir?

4) Sınıf Öğretmenleri oyun ve fiziki etkinlikler dersinde öğrencileri ne şekilde değerlendirmekte, hangi ölçme-değerlendirme yöntem ve tekniklerinden yaralanmaktadırlar?

5) Sınıf Öğretmenlerinin oyun ve fiziki etkinlikler dersinde karşılaştığı sorunlar nelerdir?

6) Sınıf Öğretmenlerinin oyun ve fiziki etkinlikler dersinde karşılaştıkları sorunlara ilişkin geliştirdikleri çözüm önerileri nelerdir?

7) Sınıf Öğretmenlerine göre öğrencilerinin oyun ve fiziki etkinlikler dersine katılımındaki istekleri nasıldır? 


\section{YÖNTEM}

Araştırmada, ilkokulda farklı sınıflarda öğretim yapan sınıf öğretmenlerinin oyun ve fiziki etkinlikler dersine ilişkin görüşleri incelenmiştir. $\mathrm{Bu}$ amaca ulaşmak için araştırmada nitel araştırma yöntemi tercih edilmiş olup durum çalışması deseni kullanılmıştır. Durum çalışması, güncel bir durumu gerçek ortamı içinde çalışan, olgu ve içinde bulunulan çevre arasında kesin sınırların olmadı̆̆ kaynağının bulunduğu, kullanıldığı araştırma yöntemidir (Şimşek ve Yıldırım, 2013). .

\section{1. Çalışma Grubu}

Çalışma 2014-2015 eğitim-öğretim y1lı bahar döneminde Muğla/Menteşe ilçesinde görev yapan toplam 20 sinıf öğretmeninin gönüllü katılımıyla gerçekleştirilmiştir. Araştırmacıların araştırma grubunu belirlerken öğretmenlere daha hızlı ve kolay bir şekilde ulaşılabilmesi için nitel araştırmalardaki örneklem türlerinden kolay ulaşılabilir durum örnekleme yöntemi kullanılmıştır.

\subsection{Veri Toplama Aracı}

Verilerin toplanmasında Kazu ve Aslan (2014) tarafından geliştirilmiş görüşme formu kullanılmıştır. Ayrıca konuyla ilgili literatür taramasıyla birlikte alan uzman görüşleri doğrultusunda düzeltmeler yapılmış ve 7 maddelik yapılandırılmış görüş alma formu uygulamada kullanılmıştır.

\subsection{Veri Toplama Süreci}

Veriler 2014-2015 eğitim öğretim bahar yarıyılında toplanmıştır. Araştırmacılar tarafından tam yapılandırılmış görüş alma formu öğretmenlere dağıtılmış, görüş alma formu için gerekli açıklama yapılmış ve öğretmenlere 20 dakika süre tanınmış olup, daha sonra formlar toplanmış ve değerlendirmeye alınmıştır.

\subsection{Verilerin Analizi}

Araştırmacılar tarafından gönüllü 20 sınıf öğretmeninin, araştırmanın amacı doğrultusunda hazırlanmış yarı yapılandırılmış görüşme formunda yer alan açık-uçlu sorular çerçevesinde görüşleri alınmış ve bu görüşlerini yazılı hale getirmeleri istenilmiştir. Verilerin analiz sürecinde betimsel analiz yöntemi tercih edilmiştir. Betimsel analiz, araştırma soruları doğrultusunda verilerin temalarının oluşturulduğu ve veri toplama aracında kullanılan yönlendirici sorular veya alt boyutlar dikkate alınarak analizin yapılmasını sağlar (Yıldırım ve Şimşek, 2013).

Araştırmada inandırıcılığı sağlamak veya arttırmak için geçerlilik ve güvenirlik kullanılan iki boyuttur. Araştırmada sonuçların geçerliğini ortaya koymak için elde edilen verilerin analiz süreci detaylı olarak araştırmacılar tarafından incelenmiştir. Araştırmada, sınıf öğretmenlerinin görüş alma formlarına yazmış oldukları görüşler 3 kodlayıcı tarafından farklı kodlanarak kategoriler üzerindeki durumdan görüş birliği veya ayrılığ 


\section{BULGULAR}

Tablo 1. Sınıf öğretmenlerinin oyun ve fiziki etkinlikler dersi kazanımlarına ilişkin görüşleri

\begin{tabular}{|c|c|c|c|}
\hline İfadeler & & & $\mathbf{F}$ \\
\hline 1 & Öğrenci seviyesine uygundur. & & 14 \\
\hline 2 & Kazanımların $\quad$ elde $\quad$ edilme & yüksektir & 3 \\
\hline 3 & Kazanımlar açıktır & & 3 \\
\hline 4 & Kazanimlar $\quad$ soyut, & değil & 2 \\
\hline 5 & Öğrenciye yararlı değil & Duyuşsal & 2 \\
\hline 6 & kazanımlar elde etme & & 2 \\
\hline 7 & Kazanımların elde edilme düzeyinde zorluk çekiliyor & & 2 \\
\hline 8 & Sınıf öğretmeni için uygun değil & & 2 \\
\hline 9 & Sentez sonrası güçlük yaşanıyor & & 1 \\
\hline \multirow[t]{2}{*}{10} & Öğrenciye uygun değil & & 1 \\
\hline & & Toplam & 32 \\
\hline
\end{tabular}

Çalışma grubunda yer alan katılımcılar görüşme formunda yer alan sorulara bir görüş belirtirken bazı katılımcılar sorulara birden fazla görüş belirtmişlerdir.

Tablo 1'e göre sınıf öğretmenlerinin çoğu kazanımların öğrenci seviyesine uygun olduğunu belirtmiştir. Bu sonuca karşın bir tane öğretmenimiz kazanımların öğrenci seviyesine uygun olmadığını belirtmiştir. Tabloda ikinci sırada kazanımların elde edilme düzeyinin yüksek olduğunu 3 öğretmen belirtirken nitekim 2 tane öğretmenimiz kazanımların elde edilme düzeyinde zorluk yaşandığını belirtmiştir. Tabloda üçüncü sırada kazanımların açık olduğunu 3 tane öğretmenimiz belirtmiştir. Nitekim tabloda dördüncü sırada kazanımların soyut ve açık olmadığını 2 öğretmenimiz belirtmiştir. Tabloda beşinci sırada kazanımların öğrenci için yaralı olmadığını iki tane öğretmenimiz belirtmiştir. Tabloda sekizinci sıraya baktığımızda 2 öğretmenin oyun ve fiziki etkinlikler dersinin sınıf öğretmeni tarafında değil beden eğitimim öğretmenleri tarafından yürütülmesinin daha yararlı olacağını belirtmiştir. Bunun yanında 1 kişi kazanımlarım kazandırılmasının sentez düzeyinde zorluk çekildiğini belirtmiştir.

Ö6 'Bu dersin kazanımları ögrenci düzeyine uygun ve açıktır.'

Ö18 'Oyun ve Fiziki Etkinlikler dersinin kazanımları ögrenciye uygun ve açıktır. Kazanımları elde etme düzeyi yüksektir.'

Tablo 2. Sınıf öğretmenlerinin oyun ve fiziki etkinlikler dersinin ders kitaplarına ilişkin görüşleri

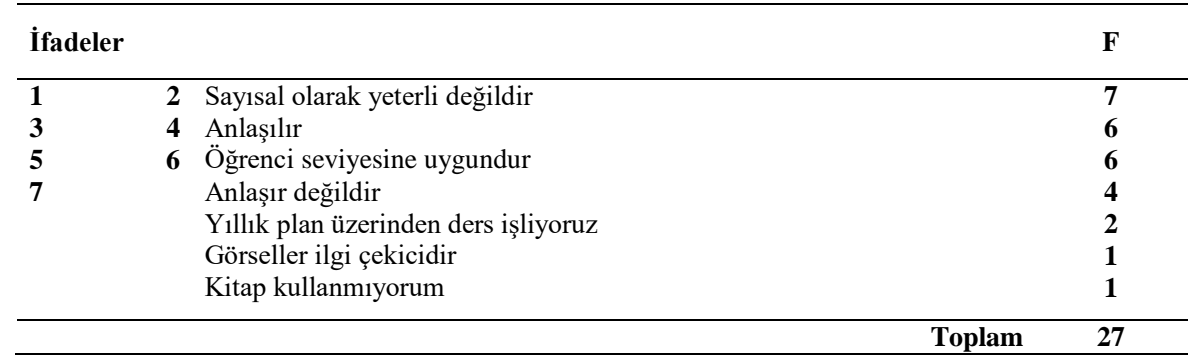

Çalışma grubunda yer alan katılımcılar görüşme formunda yer alan sorulara bir görüş belirtirken bazı katılımcılar sorulara birden fazla görüş belirtmişlerdir. 
Tablo 2'ye göre sınıf öğretmenlerinin çoğu etkinliklerin sayısal olarak yeterli olmadığını belirtmiştir. Öğretmenlerden 6 kişi oyun ve fiziki etkinlikler dersi kitapların anlaşılır olduğunu belirtmiştir. Nitekim 4 kişi öğretmen ders kitapların anlaşır olmadığını belirtmiştir. Tablonun ikinci sırasında kitapların öğrenci seviyesine uygun olduğunu 6 kişi belirtmiştir. Ayrıca 1 öğretmen kitaptaki görsellerin ilgi çekici olduğunu belirtmiştir. 1 öğretmen ders kitabı kullanmadığını belirtmiştir. 2 kişide yıllık plan üzerinde dersini işlediğini belirtmiştir.

Ö20' Oyun ve Fiziki Etkinlikler ders kitabı anlaşılır olmalı ve etkinlik sayısı yeterli sayıda değildir.'

Ö13 'Etkinlikler kitaplarında biraz ayrıntıya girilmeli ve etkinlik çeşidi arttırllmalıdır.

Tablo 3. Sınıf öğretmenlerinin oyun ve fiziki etkinlikler dersinde hangi etkinliklere öncelik verildiğine ilişkin görüşleri

\begin{tabular}{cclc}
\hline \multicolumn{2}{c}{ İfadeler } & & F \\
\hline $\mathbf{1}$ & $\mathbf{2}$ & Serbest bahçe oyunları & $\mathbf{1 2}$ \\
$\mathbf{3}$ & $\mathbf{4}$ & Boyama-Resim & $\mathbf{1 1}$ \\
$\mathbf{5}$ & $\mathbf{6}$ & Okuma çalışmaları & $\mathbf{6}$ \\
$\mathbf{7}$ & $\mathbf{8}$ & Şarkı & $\mathbf{5}$ \\
& & Bedensel Faaliyet & $\mathbf{5}$ \\
& & Yazma çalışması & $\mathbf{5}$ \\
& & Koşu & $\mathbf{4}$ \\
& & Sinıf oyunları & $\mathbf{3}$ \\
\hline & & & $\mathbf{5 1}$ \\
\hline
\end{tabular}

Çalışma grubunda yer alan katılımcılar görüşme formunda yer alan sorulara bir görüş belirtirken bazı katılımcılar sorulara birden fazla görüş belirtmişlerdir.

Tablo 3'e göre sınıf öğretmenlerinin çoğu serbest bahçe oyunları ve boyamaresim etkinlikleri yaptıkları görülmüştür. Bununla birlikte sınıf öğretmenleri oyun ve fiziki etkinlikler dersinde okuma çalışmaları, şarkı, bedensel faaliyetler, yazma çalışmaları, koşu, sınıf oyunlarına yer verdiklerini belirtmişlerdir.

Ö19 'Oyun ve Fiziki Etkilikler dersinde serbest bahçe oyunlarına öncelik veriyorum.'

Tablo 4. Sınıf öğretmenlerinin oyun ve fiziki etkinlikler dersinde öğrencilerinizi nasıl değerlendirmekte, hangi ölçme-değerlendirme yöntem ve teknikleri kullandıklarına ilişkin görüşler

\begin{tabular}{clc} 
İfadeler & & F \\
& & $\mathbf{7}$ \\
$\mathbf{1}$ & Gözlem & $\mathbf{6}$ \\
$\mathbf{2}$ & Derse yönelik tutum ve katılım & $\mathbf{5}$ \\
$\mathbf{3}$ & Oyunu doğru uygulaması & $\mathbf{4}$ \\
$\mathbf{4}$ & Ölçme aracı kullanmiyorum & $\mathbf{4}$ \\
$\mathbf{5}$ & Performans değerlendirme ölçeği & $\mathbf{2}$ \\
$\mathbf{6}$ & Oyun kurallarına uyma & $\mathbf{1}$ \\
$\mathbf{7}$ & Süreç değerlendirme ölçekleri & $\mathbf{1}$ \\
$\mathbf{8}$ & Öz değerlendirme & $\mathbf{1}$ \\
$\mathbf{9}$ & Akran değerlendirme & $\mathbf{3 1}$ \\
\hline
\end{tabular}


Çalışma grubunda yer alan katılımcılar görüşme formunda yer alan sorulara bir görüş belirtirken bazı katılımcılar sorulara birden fazla görüş belirtmişlerdir.

Tablo 4'e göre sınıf öğretmenlerinin çoğu oyun ve fiziki etkinlikler dersinde ölçme ve değerlendirmede gözlem yöntemini kullandığını belirtmişlerdir. Bunun yanında öğretmenlerin derse yönelik tutum ve katılı, oyunun doğru uygulanması, performans değerlendirme, süreç değerlendirme ölçekleri kullandıklarını söylemiştir. Nitekim tablonun dördüncü kısmında 4 kișinin ölçme aracı kullanmadığını belirtmiştir. Buda öğretmenlerin oyun ve fiziki etkinlikler öğretim programla ilgili yeterli bilgiye sahip olamadığını göstermektedir.

Ö13 'Öğrencileri dĕgerlendirirken gözlem yöntemini kullanıyorum.'

Ö1 'Herhangi bir ölçme değerlendirme aracı kullanmıyorum. Öğrencilerin derse katılım ve ders sırasında gösterdiği tutum ve davranışlara göre dĕgerlendirme yapmaktayım.'

Tablo 5. Sınıf öğretmenlerinin oyun ve fiziki etkinlikler dersinde karşılaştığı sorunlarla ilgili görüşler

\begin{tabular}{clc}
\hline İfadeler & & $\mathbf{F}$ \\
\hline $\mathbf{1}$ & Malzeme yetersizliği & $\mathbf{1 4}$ \\
$\mathbf{2}$ & Uygun alan olmaması & $\mathbf{1 0}$ \\
$\mathbf{3}$ & Diğer derslere ilgisizlik & $\mathbf{2}$ \\
$\mathbf{4}$ & Ders saati fazla & $\mathbf{2}$ \\
$\mathbf{5}$ & Öğrenci Kitabı & $\mathbf{1}$ \\
$\mathbf{6}$ & kitap kaynak yok & $\mathbf{1}$ \\
$\mathbf{7}$ & Sinıf ŏğretmenliğin yetersizliği & $\mathbf{1}$ \\
$\mathbf{8}$ & Öğrenciye uygun olmaması & $\mathbf{1}$ \\
$\mathbf{9}$ & Oyunlara yer verilmemesi & $\mathbf{1}$
\end{tabular}

\section{Toplam}

Çalışma grubunda yer alan katılımcılar görüşme formunda yer alan sorulara bir görüş belirtirken bazı katılımcılar sorulara birden fazla görüş belirtmişlerdir.

Tablo 5'de sınıf öğretmenleri oyun ve fiziki etkinlikler dersinde karşılaştığ1 sorunlarla ilgili sınıf ögretmenlerinin birçoğu oyun ve fiziki etkinliğin yapılacağı bir alan olmaması, malzeme yetersizliğinden kaynaklı sorun olduğu söylemiştir. Bunun yanında diğer derslere ilgisizlik, ders saatin fazla olması, öğrencinin kitap kaynağının olmaması, sınıf öğretmenlerin derse ilişkin yetersizliği, öğrenciye uygun olmaması, oyunlara yer vermemesi gibi sorunları belirtmişlerdir.

Ö12' Ders saatinin fazla olması, araç ve gereç yetersizliğinde kaynaklı sorunlar var.'

Ö17 'Oyun ve Fiziki Etkinlik alanının olmaması, uygun araç gereç sağlanamamast.' 
Tablo 6. Sınıf öğretmenlerinin oyun ve fiziki etkinlikler dersinde karşılaştığı sorunların çözümüne ilişkin görüşleri

\begin{tabular}{clc}
\hline İfadeler & & $\mathbf{F}$ \\
\hline $\mathbf{1}$ & Materyal malzeme temini & $\mathbf{1 8}$ \\
$\mathbf{2}$ & OFE alanı oluşturulmalı & $\mathbf{6}$ \\
$\mathbf{3}$ & Alternatif oyunlar & $\mathbf{2}$ \\
$\mathbf{4}$ & Ders saati azaltılmalı & $\mathbf{2}$ \\
$\mathbf{5}$ & Dersi beden eğitimi öğret. vermeli & $\mathbf{1}$ \\
$\mathbf{6}$ & Oyuncak olmalı & $\mathbf{1}$ \\
$\mathbf{7}$ & Yöneticiler ilgilensin biz ne desek boş & $\mathbf{1}$ \\
$\mathbf{8}$ & Öğrenci seviyesine uygun etkinlik yok & $\mathbf{1}$ \\
& & $\mathbf{3 2}$ \\
\hline
\end{tabular}

Çalışma grubunda yer alan katılımcılar görüşme formunda yer alan sorulara bir görüş belirtirken bazı katılımcılar sorulara birden fazla görüş belirtmişlerdir.

Tablo 6'ya sınıf öğretmenlerinin çoğu Oyun ve Fiziki etkinliklere karşı çözüm önerisinde materyal malzeme temini yapılması gerektiğini belirtmişlerdir. Tablonun ikinci kısmında Oyun ve Fiziki etkinlik ders alanı oluşturulması gerektiğini 6 kişi söylemiştir. Ayrıca öğretmenler alternatif oyunlar, ders saatinin azaltılması, dersi beden eğitimi öğretmenlerin vermesi gerektiği, oyuncakların ders materyali olarak kullanılabilir gibi önerilerde bulunmuşlardır.

Ö2 'Oyun ve Fiziki Etkinlik alanı ve malzeme ihtiyacı karşılanmalıdır.'

Ö10 ' Oyun ve Fiziki Etkinliklerde ögrencilere alternatif oyunlar sunulmall, çeşitli oyuncaklar olmalıdır.'

Tablo 7. Sınıf öğretmenlerine göre öğrencilerin oyun ve fiziki etkinlikler dersine katılımında isteklerine ilişkin görüşler

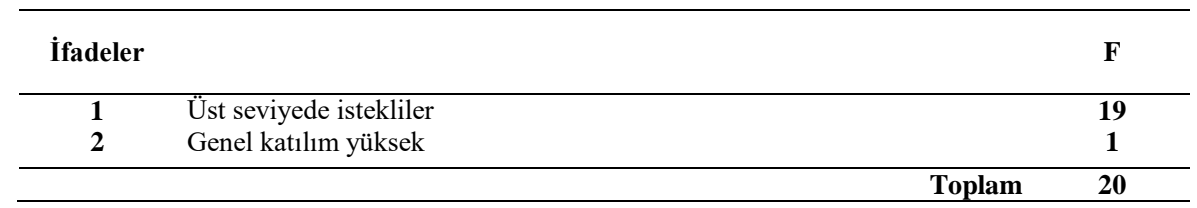

Çalışma grubunda yer alan katılımcılar görüşme formunda yer alan sorulara bir görüş belirtirken bazı katılımcılar sorulara birden fazla görüş belirtmişlerdir.

Tablo 7'de sınıf öğretmenlerimiz Oyun ve fiziki etkinlikler dersinde öğrencilerin derse katılımdaki tutumları ile ilgili görüşlerinin üst seviyede istekli olduğunu söylemişlerdir. Bunun dışında öğrencilerin oyun ve fiziki etkinlikler dersine katılım yüksek olduğunu söylemiştir.

Ö4 'Daha rahat ve serbest bir ders ortamı olduğu için ögrenciler daha istekli ve rahat oluyorlar. Ö15 'Ögrrenciler heyecanl, dört gözle Oyun ve Fiziki Etkinlik dersini bekliyorlar.'

\section{TARTIŞMA ve SONUÇ}

2012 yılında yapılan bir düzenleme ile Milli Eğitim Bakanlığının 4+4+4 eğitim sistemini uygulamaya geçmesi ile birlikte ilkokul dört yıla indirilmiş, ilkokul programlarında yapılan değişiklikler ile birlikte 2012-2013 eğitim-öğretim yılından 
itibaren ilkokul programlarında "Oyun ve Fiziki Etkinlikler" dersi yer almaktadır. Uygulamaya konulan bu dersin amacı ilkokul öğrencilerinin yaşamları süresince kullanacakları temel hareketler, kavramlar ve stratejilere dayalı düzenli ve sağlıklı yaşam becerileri geliştirerek sonraki eğitim durumlarına hazırlanmalarını sağlamaktır. Buradan hareketle oyun ve fiziki etkinlikler dersi ile ilgili ilkokullarda görev yapan sınıf öğretmenlerinin görüşlerinin belirlenmesi önemlidir.

Uygulamaya konulan oyun ve fiziki etkinlikler dersinin kazanımları ilişkin görüşlerine bakıldığında, sınıf öğretmenlerinin büyük bir kısmının (\% 44) dersin kazanımlarının öğrencilerin gelişimlerine uygun olduğu yönünde görüş belirttikleri görülmektedir. Buna sonuca paralel olarak Dalaman ve Korkmaz'in (2010) tarafından yapılan çalışmasındaki bulgular ile bizim bulduğumuz bulgular benzerlik göstermektedir.

Oyun ve fiziki etkinlikler dersi ile ilgili hazırlanan ders kitaplarının uygunluğuna ilişkin olarak, sınıf öğretmenlerinin büyük bir kısmı (\% 26) ders kitaplarındaki etkinlik sayılarının yeterli seviyede olmadığını ortaya koymuşlardır.

Oyun ve fiziki etkinlikler dersinde uygulanan etkinliklere ilişkin olarak, sınıf öğretmenlerinin büyük bir kısmı (\%45) serbest bahçe oyunları ve boyama - resim oynattığını belirtmiştir. İlkokul programında yer alan bu derste, öğrencilerin yaşamları süresince kullanacakları temel hareketler, aktif, düzenli ve sağlıklı yaşam becerileri geliştirilerek bir sonraki eğitim hayatına hazırlamak amaçlanmıştır. Yapılan etkinlikler dersin amaçlarının gerçekleşmesine etkisi vardır.

Oyun ve fiziki etkinlikler dersi kapsamında kullanılan ölçme-değerlendirme araçları doğrultusunda, sınıf öğretmenlerinin büyük bir kısmı (\%22) gözlem formları kullanmaktadırlar. Bunun yanında öğretmenlerin derse yönelik tutum ve katılım, oyunun doğru uygulanması, performans değerlendirme, süreç değerlendirme ölçekleri kullandıklarını söylemiştir. Bu sonuç Avşar (2009) tarafından yapılan araştırmanın bulguları ile benzerlik göstermektedir.

Oyun ve fiziki etkinlikler dersinde yaşanan sorunlarla ilgili olarak, sınıf öğretmenlerinin büyük bir kısmı (\%41) materyal malzeme, oyun ve fiziki etkinlik ortamı yetersizliğinden dolayı sorun yaşadıkları belirtmiştir. Çalışmada elde edilen bu bulgular, Dağdelen ve Kösterelioğlu (2015), Kazu ve Arslan (2014), Boz ve Yıldırım (2014), Tokat (2013) Gülüm ve Bilir (2011) tarafından yapılan çalışmalar ile benzerlik gösterir. Oyun ve Fiziki dersinde materyal malzeme ve ortam yetersizliği dersin amaçlarını gerçekleştirmede sorunlar yaratacaktır.

Oyun ve fiziki etkinlikler dersinde karşılaşılan sorunların giderilmesine yönelik sınıf öğretmenlerinin geliştirdiği önerilerde öğretmenlerin büyük bir kısmı $(\% 58)$ oyun ve fiziki etkinlikler dersine ilişkin kullanılan öğretim programındaki araç gereçlere ilişkin öneri geliştirdikleri görülmektedir. Buna paralel olarak Dağdelen ve Kösterelioğlu 2015; Kazu ve Arslan'ın 2014; Aras, 2013; Gülüm ve Bilir, 2011; çalışmalarındaki bulgular ile bizim çalışmamızdaki bulgular benzerlik gösterir.

Oyun ve Fiziki Etkinlikler dersine katılımında ilgili görüşler bakıldığında öğretmenlerin çoğu (\%95) öğrencilerin üst seviyede istekli olduğunu söylemişlerdir. Öğrencilerin oyun ve fiziki etkinlikler dersine katılımın üst seviyede istekli olmasında derste öğrencilerin duygularını rahatça ifade etmesi, rahat ve bağımsız bir ortam olması, mutluluk sağlayan eğlenceli bir ortam sağlaması ve çocuğun gelişim alanlarını destekleyen etkinlikleri içermesinin etkisi düşünülebilir. 
Araştırmada elde edilen sonuçlara bağlı kalınarak sınıf öğretmenleri, araştırmacılar ve uzmanlara aşağıdaki öneriler sunulmuştur.

1. Oyun ve Fiziki Etkinlikler dersinde kullanılabilecek eğitim materyalleri temin edilip bu okullara gönderilmelidir.

2. Okullarda Oyun ve Fiziki Etkinlikler dersinin amaçlarına uygun ve etkili bir ders işlenişinin sağlanacağı fiziki ortamlar meydana getirilmelidir.

3. Oyun ve Fiziki Etkinlikler dersi kapsamında hazırlanan ders kitaplarında etkinlik sayılarının arttırılması yararlı olacaktır.

4. Oyun ve Fiziki Etkinlikler dersi kapsamında sağlıklı bir ölçmedeğerlendirme yapılması için bu boyutun daha dikkatli bir şekilde irdelenmesi için sınıf öğretmenlerinin bilgilendirilmesi gerekli görülmektedir.

5. Oyun ve Fiziki Etkinlikler dersine yönelik sınıf öğretmenlerine dersin önemini kavratacak hizmet içi eğitim seminerleri, alan uzmanları tarafinda verilmelidir.

Eğitim fakültelerinin sınıf öğretmenliği bölümlerinde, sınıf öğretmeni adaylarının, Beden ve Oyun Eğitimi ders saat sayısı arttırılıp, bu ders alan uzmanları tarafindan verilmelidir. 


\section{KAYNAKLAR}

Avşar, Z. (2009). İlköğretim Öğrencilerinin Beden Eğitimi Dersi Değerlendirme Süreci İle İlgili Görüşlerinin Belirlenmesi. Spor Bilimleri Dergisi, 20 (3), 81-89.

Aras, Ö. (2013). İlköğretim Kurumları İkinci Kademede Öğrenim Gören Öğrenci ve Görev Yapan Beden Eğitimi Öğretmenlerinin Beden Eğitimi Dersine Yönelik Görüş ve Tutumlarının İncelenmesi (Kars ili örneği). Yüksek lisans tezi, Gazi Üniversitesi Eğitim Bilimleri Enstitüsü, Ankara.

Boz, T. ve Yıldırım, A. (2014). "4+4+4 Eğitim Sisteminde Birinci Sınıf Öğretmenlerinin Karşılaştığı Zorluklar.” Başkent Unıversıty Journal of Education, 1(2): 54-65.

Can, S. (2015). Ders Notları

Cihangiroğlu, C. (1994). Çocuk Oyun Alanlarındaki Oyun Aletlerinde Uyulması Gereken Kriterler Üzerine Bir Araştırma. Yayımlanmamış yüksek lisans tezi, Ankara Üniversitesi, Fen Bilimleri Enstitüsü, Ankara.

Dağdelen, O. ve Kösterelioğlu, İ. (2015). İlkokullardaki Oyun Ve Fiziki Etkinlikler Dersinin Öğretmen Görüşlerine Göre Değerlendirilmesi. Adıyaman Üniversitesi Sosyal Bilimler Enstitüsü Dergisi Issn: 1308-9196, Y1l : 8 Sayı : 19, DOI Numarasi:http://dx.doi.org/10.14520/adyusbd.35272

Dalaman, O.ve Korkmaz, İ. (2010). İlköğretim Birinci Kademede Beden Eğitimi Dersine Giren Öğretmenlerin Beden Eğitimi Öğretim Programı Kazanımlarına İlişkin Görüşleri. Niğde Üniversitesi Beden Eğitimi Ve Spor Bilimleri Dergisi Cilt 4, Say1 3.

Erdem, Ö. (2003). Okul Öncesi Eğitim Birimlerinde Dış Mekân Tasarım İlkeleri. Yayımlanmamış yüksek lisans tezi, Ankara Üniversitesi, Fen Bilimleri Enstitüsü, Ankara.

Gülüm, V. ve Bilir, P. (2011). Beden Eğitimi Öğretim Programının Uygulanabilme Koşulları ile ilgili Beden Eğitimi Öğretmenlerinin Görüşleri. Spormetre Beden Eğitimi ve Spor Bilimleri Dergisi, 9(2), 57-64.

Kazu, H. ve Arslan, S. (2014). Oyun Ve Fiziki Etkinlikler Dersinin Birinci Sinıf Öğretmenlerinin Görüşlerine Göre Değerlendirilmesi (Elazı̆̆ İli Örneği). Fırat Üniversitesi Sosyal Bilimler Dergisi, Cilt: 24, Say1: 1, Sayfa: 49-63.

MEB. (2012a). Oyun ve Fiziki Etkinlikler Dersi Öğretim Programı. Ankara: Milli Eğitim Bakanlığı Yayınları.

MEB. (2012b). Güzel Sanatlar ve Spor Liseleri Eğitsel Oyunlar. Ankara Milli Eğitim Bakanları Yayınları.

Özdenk, Ç. (2007). 6 Yaş Grubu Öğrencilerinin Psikomotor Gelişimlerinin Sağlanmasında Oyunun Yeri ve Önemi. Fırat Üniversitesi Sosyal Bilimler Enstitüsü (Yayımlanmamış Yüksek Lisans Tezi).

Poyraz, H. (2003). Okul Öncesi Dönemde Oyun ve Oyuncak. Ankara: Anı Yayıncılık

Tokat, S. (2013). Beden Eğitimi Öğretmenleri ve Okul Yöneticilerinin Beden Eğitimi ve Spor Dersinin Etkinliği Üzerine Görüşlerinin İncelenmesi. Yüksek lisans tezi, Gazi Üniversitesi Eğitim Bilimleri Enstitüsü, Ankara.

Uluğ, M. (1999). Niçin Oyun? Çocuğun Gelişiminde ve Çocuğu Tanımada Oyunun Önemi. İstanbul: Özne ve Göçebe Yayınları.

Yıldırım, A. ve Şimşek, H. (2013). Sosyal bilimlerde nitel araştırma yöntemleri. Ankara: Seçkin Yayınevi. 


\section{EXTENDED ABSTRACT}

\section{Introduction}

For elementary school students, play is a means of both learning and entertainment. Therefore, it seems to be of great importance to meet elementary school students' needs for play and physical activity. Various research has revealed that for children to protect their health, they need to be engaged in plays or physical activities at least an hour a day. Thus, in 2012-2013, the course of "Play and Physical Activities" was incorporated into the elementary school program. The main objective of this course is to develop elementary school students' basic movements, active and healthy life skills, concepts and strategies so that they can be ready for further stages of schooling.

Play directly affects the whole developmental process of an individual. Though how it affects varies depending on the characteristics of the game, it is true that it somehow affects the development of an individual. We can summarize the benefits of play as follows (Cihangiroğlu, 1994; Erdem, 2003).

1) It helps students to get to know their bodies.

2) It contributes to their emotional and social development.

3) It makes students get to know themselves better.

4) It prepares students for life.

5) While students are playing, they give up their selfish thoughts and learn how to respect others' rights, to protect their own rights and freedoms and they also find opportunities to develop their qualifications such as leadership, competitiveness, solidarity, cooperation, self-esteem and self-confidence.

6) Through play, students find opportunities to practice and develop what they have learned.

7) Students' thinking and idea-production skills improve and they can test these skills during play.

8) It improves students' communication skill.

In this regard, the current study aimed to evaluate the course of play and physical activities on the basis of elementary school teachers' opinions. To this end, answers to the following questions were sought:

1) What are the classroom teachers' opinions about the objectives of the play and physical activities course?

2) What are the classroom teachers' opinions about the textbooks of the play and physical activities course?

3) What are the activities to which greater priority is attached by the classroom teachers within the play and physical activities course?

4) Which measurement and evaluation methods and techniques do the classroom teachers use while assessing students in the play and physical activities course?

5) What are the problems encountered by the classroom teachers in the play and physical activities course?

6) What are the solutions suggested by the classroom teachers to the problems they are confronted with in the play and physical activities course?

7) How is the motivation of students to participate in the play and physical activities course according to the classroom teachers?

\section{Method}

The current study employed the case study method, one of the qualitative research methods. Case study is a research method widely used to investigate a phenomenon in its natural environment where the borders between the phenomenon and its surrounding are not clear and 
there are more than one source of data or evidence (Şimşek and Yıldırım, 2013). The study group of the current research is comprised of 20 classroom teachers working at schools located in the Menteşe province of the city of Muğla in the spring term of 2014-2015 school year. In order to reach the teachers faster and more easily, the convenience sampling method, one of the sampling methods used in qualitative research, was employed in the current study. The data were collected by using the questionnaire form developed by Kazu and Aslan (2014). In the analysis of the data, the descriptive analysis method was used. The descriptive analysis method allows the organization of the data according to the themes revealed by research questions and the presentation of them considering the items or dimensions used in the collection of the data (Yıldırım and Şimşek, 2013).

\section{Result}

The results of the study are as follows:

1. Of the participating teachers, $44 \%$ think that the objectives of the play and physical activities course program are in compliance with the developmental level of students. Similar findings are reported by Dalaman and Korkmaz (2010).

2. Some of the teachers (26\%) stated that the number of activities in the textbooks prepared for the course of play and physical activities is not adequate.

3. In relation to the activities conducted within the play and physical activities course, nearly half of the teachers $(45 \%)$ stated that they prefer to let children play freely in the school garden and paint.

4. When the teachers' opinions about the measurement-evaluation methods and techniques adopted for the course of play and physical activities are examined, it is seen that $22 \%$ of them use observation forms to assess their students. In addition to this, the teachers also evaluate their students on the basis of their attitudes towards activities, participation in them and performance

5. In terms of the problems encountered in the play and physical activities course, $41 \%$ of them stated that they experience problems arising from the inadequacies concerning materials, equipments and the setting of the play and activities.

6. When the suggestions for solutions to these problems are examined, it is seen that $58 \%$ of the teachers made suggestions related to provision of the materials required for the effective implementation of the play and physical activities course program.

7. When the teachers' opinions about students' motivation to participate in the play and physical activities course are examined, it is seen that $95 \%$ of them think that students are highly motivated to participate.

In light of these results, following suggestions can be made:

6. Educational materials that can be used in play and physical activities classes should be provided and sent to schools in need of them.

7. Physical conditions necessary for the play and physical activities course should be provided.

8. Increasing the number of the activities in the textbooks of the play and physical activities course can be useful.

9. Teachers should be informed about the measurement-evaluation dimension of the play and physical activities course program.

10. In-service training seminars should be given by field experts to improve teachers' grasp of the importance of the play and physical activities course.

In the classroom teacher training departments of education faculties, class hours allocated for the play and physical activities course should be increased and these classes should be taught by field experts. 